\title{
Article \\ Retrospective Analysis of the Effect of Three-Dimensional Preformed Titanium Mesh on Peri-Implant Non-Contained Horizontal Defects in 100 Consecutive Cases
}

\author{
In-Oh Choi ${ }^{1}{ }^{\mathbb{D}}$, Ji-Su Oh ${ }^{2}$, Sang-Joun $\mathrm{Yu}^{1}{ }^{1}$, Byung-Ock Kim ${ }^{1}$ and Won-Pyo Lee ${ }^{1, *(\mathbb{D})}$ \\ 1 Department of Periodontology, School of Dentistry, Chosun University, Gwangju 61452, Korea; \\ inono10@gmail.com (I.-O.C.); sjyu78@chosun.ac.kr (S.-J.Y.); bobkim@chosun.ac.kr (B.-O.K.) \\ 2 Department of Oral and Maxillofacial Surgery, School of Dentistry, Chosun University, Gwangju 61452, Korea; \\ jsoh@chosun.ac.kr \\ * Correspondence: wplee8@chosun.ac.kr; Tel.: +82-62-220-3850
}

check for updates

Citation: Choi, I.-O.; Oh, J.-S.; Yu,

S.-J.; Kim, B.-O.; Lee, W.-P.

Retrospective Analysis of the Effect of Three-Dimensional Preformed Titanium Mesh on Peri-Implant Non-Contained Horizontal Defects in 100 Consecutive Cases. Appl. Sci. 2021, 11, 872. https://doi.org/ 10.3390/app11020872

Received: 20 December 2020

Accepted: 17 January 2021

Published: 19 January 2021

Publisher's Note: MDPI stays neutral with regard to jurisdictional claims in published maps and institutional affiliations.

Copyright: (c) 2021 by the authors. Licensee MDPI, Basel, Switzerland. This article is an open access article distributed under the terms and conditions of the Creative Commons Attribution (CC BY) license (https:// creativecommons.org/licenses/by/ $4.0 /)$.
Featured Application: The three-dimensional preformed titanium (Ti) mesh is easy to use because there is no need to cut or bend it. Ti-mesh fixation is also simpler than the traditional Ti-mesh; therefore, a dentist can easily improve the prognosis of guided bone regeneration, especially for peri-implant non-contained defects.

Abstract: This study aimed to clinically and radiographically evaluate the results of guided bone regeneration (GBR) using three-dimensional preformed titanium mesh (3-D-PFTM) for non-contained horizontal defects in 100 consecutive cases. This study involved 100 patients (129 implants) with peri-implant non-contained horizontal defects. The patients were divided into three groups: 3-DPFTM alone (Group 1), 3-D-PFTM plus cross-linked collagen membrane (Group 2), and 3-D-PFTM plus non-cross-linked collagen membrane (Group 3). Each implant was evaluated radiographically using $\mathrm{CBCT}$ at baseline and 6 months postoperatively. At the platform level, the mean horizontal hard tissue gain of all the sites was $3.1 \pm 1.3 \mathrm{~mm}$ at 6 months postoperatively. The mean rate of mesh exposure was $11.8 \%$ in Group 1, $4.2 \%$ in Group 2, and 5.0\% in Group 3. The mean hard tissue gain rate was $71.0 \pm 23.0 \%$ in group $1,84.2 \pm 21.5 \%$ in group 2 , and $84.0 \pm 22.9 \%$ in group 3 . Groups 2 and 3 showed significantly higher hard tissue gain rates than group 1 . However, there was no significant difference between the rates in groups 2 and 3. Within the limitations of this study, 3-D-PFTM should be considered as a valuable option for GBR for peri-implant non-contained horizontal defects. The use of an additional resorbable collagen membrane provides additional advantages.

Keywords: bone regeneration; dental implants; titanium

\section{Introduction}

Sufficient bone mass is important for the long-term prognosis of implants [1]. However, horizontal or vertical bone mass is often insufficient, and various techniques have been introduced for atrophic alveolar bones, including autologous onlay block bone graft, sinus floor elevation, rigid splitting, and guided bone regeneration (GBR) [2-5]. The survival rates of implants after each procedure, according to a study, were as follows: maxillary sinus lift, 91.5\%; onlay bone grafting, 85.2\%; GBR, 96.1-100\%. Owing to its high success rate and surgical convenience, GBR has become the most commonly used technique [6].

Among the several GBR methods, the technique involving particle bone and resorbable collagen membrane is presently the most used method for bone regeneration [7]. Resorbable collagen membranes have several advantages, including a low risk of tissue damage, better cost-benefit ratio, ease of use, and the non-requirement of secondary surgery. However, it has fatal shortcomings, such as the unpredictable absorption rate of the membrane and the lack of space maintenance $[8,9]$. Therefore, predictable results can 
be obtained for closed and intrabony, but not for extrabony defects, and this limits it [10]. The prognosis of GBR using a resorbable membrane is further worsened in an extrabony defect that does not exist within the envelope of adjacent bone [11].

Various materials have been used to compensate for the limitations of the resorbable membranes. Some methods use titanium-reinforced d-PTFE or titanium (Ti) mesh [12]. These methods can facilitate satisfactory results for GBR for extrabony defects, but they have high technical sensitivity because of the need for additional surgery to remove the membrane and the high membrane exposure rate. As a material for compensating for the disadvantages of the conventional Ti-mesh, a three-dimensional preformed Ti mesh (3-D preformed Ti mesh) was introduced. Lee et al. reported that a 3-D preformed Ti mesh can improve the prognosis of alveolar ridge augmentation, which is also easy to use because it does not need to be cut or bent, and it reduces the surgery duration and the exposure rate of the mesh by avoiding sharp edges. In addition, it has been reported that minimal invasion of the bone graft site during the second surgery is advantageous because GBR application to the bony defect around the implant can be simultaneous with implant placement [13].

This study aimed to retrospectively evaluate the clinical and radiological findings of GBR in 100 consecutive patients (129 sites) who underwent the simultaneous application of the 3-D preformed Ti mesh to the non-contained horizontal defects around the implant. The study's working hypothesis was that the use of additional two types of resorbable collagen membranes with a 3-D preformed Ti mesh would affect the hard tissue gain rate.

\section{Materials and Methods}

\subsection{Patient Selection}

Among the patients who visited the periodontal department of Chosun University Dental Hospital between September 2016 and April 2018, we selected those who underwent alveolar bone augmentation with 3-D preformed Ti mesh (Oss-Builder ${ }^{\circledR}$ type I; Osstem, Busan, Korea) and freeze-dried particulate bone allografts (Do bone ${ }^{\circledR}$, Renew Medical Co., Bucheon, Korea) for non-contained horizontal defects of the buccal region around the implant at the same time the implant was placed in this study. One hundred patients (39 men, 61 women) were selected, and their ages ranged from 20 to 82 years (average, $57.1 \pm 15.5$ ) (Table 1). The patients were selected based on the following criteria: (i) having non-contained horizontal defects in the buccal area at the platform level after implant placement. On the other hand, patients satisfying the following criteria were excluded: (i) vertical bone augmentation and (ii) non-contained horizontal defects with no implant thread exposure. The selected patients were grouped into three: a group using only a 3-D preformed Ti mesh for GBR, a group using a cross-linked collagen membrane above the Ti mesh, and a group using an additional non-cross-linked collagen membrane. This study was conducted with the approval of the Institutional Review Board (IRB) of the Dental Hospital of Chosun University in Gwangju, Korea (CUDHIRB-1806-005). All treatment plans and procedures were explained to the patients, and they provided consent for surgery.

Table 1. Characteristics of the subjects.

\begin{tabular}{ccccc}
\hline & $\begin{array}{c}\text { Only } \\
\text { 3-D-PFTM } \\
\text { (Group 1) }\end{array}$ & $\begin{array}{c}\text { 3-D-PFTM + CCM } \\
\text { (Group 2) }\end{array}$ & $\begin{array}{c}\text { 3-D-PFTM + NCCM } \\
\text { (Group 3) }\end{array}$ & Total \\
\hline N of subjects $\left(\mathrm{N}_{\mathrm{s}}\right)$ & 15 & 56 & 29 & 100 \\
N of sites $\left(\mathrm{N}_{\mathrm{i}}\right)$ & 17 & 72 & 40 & 129 \\
Mean age (range) & $64.5 \pm 16.9$ & $56.5 \pm 14.0$ & $54.4 \pm 17.2$ & $57.1 \pm 15.5$ \\
Gender & $(33-82)$ & $(21-81)$ & $(20-80)$ & $(20-82)$ \\
Men, $\mathrm{N}_{\mathrm{S}}\left(\mathrm{N}_{\mathrm{i}}\right)$ & $7(8)$ & $19(21)$ & $13(17)$ & 16 (23) \\
Women, $\mathrm{N}_{\mathrm{s}}\left(\mathrm{N}_{\mathrm{i}}\right)$ & $8(9)$ & $37(51)$ & $61(83)$ \\
\hline
\end{tabular}

$\mathrm{N}$, number; $\mathrm{N}_{\mathrm{s}}$, number of subjects; $\mathrm{N}_{\mathrm{i}}$, number of sites (implants); 3-D-PFTM, three-dimensional preformed titanium mesh; CCM, cross-linked collagen membrane; NCCM, non-cross-linked collagen membrane. 


\subsection{Surgical Procedure}

All surgical procedures were performed by a single skilled periodontologist (W.P.L.). Gargling was performed for $1 \mathrm{~min}$ using a $0.12 \%$ chlorhexidine solution before surgery. After local anesthesia with $2 \%$ lidocaine containing epinephrine (1: 100,000), bone exposure was facilitated by lifting a full-thickness flap after alveolar ridge incision and vertical incision with a \#15 surgical blade (Figure 1A). After curettage of the inflamed tissue, cortical bone perforation was performed using a \#330 carbide burr for a bone graft. One hundred and twenty-nine implants of two types (TS III SA ${ }^{\circledR}$, Osstem, Seoul, Korea; Superline ${ }^{\circledR}$, Dentium, Seoul, Korea) were placed using standard methods in 100 patients (Figure 1B,C). In all cases, the implant thread was partially exposed to the buccal area, and the GBR procedure was performed on the extrabony defects. First of all, to obtain platelet-rich fibrin (PRF) solution, which was mixed with graft material, $10 \mathrm{~mL}$ of blood was drawn from each participant through venipuncture of the left or right arm and placed in sterilized plastic vacuum tubes devoid of silica from their inner surface. Subsequently, the blood samples were centrifuged for $10 \mathrm{~min}$ at $400 \times g\left(\mathrm{MF} 300^{\circledR}\right.$, Hanil Science Industrial Co., Incheon, Korea). After centrifugation, the supernatant, which consisted of acellular plasma, was aspirated using syringes. An allograft bone (Do bone ${ }^{\circledR}$, CGBio, Seongnam, Korea) and this (PRF) solution were mixed and grafted onto the non-contained horizontal defects after a $1 \mathrm{~mm}$ anchor screw was fastened to the implant. Thereafter, a 3-D preformed Ti mesh was applied. Subsequently, the mesh was easily fixed to the anchor screw using a $0.3 \mathrm{~mm}$ cover screw (Figure 1D). In 15 patients, only a 3-D preformed Ti mesh was used. A cross-linked resorbable collagen membrane (Ossix Plus ${ }^{\circledR}$, Datum Dental Biotech, Lod, Israel) was additionally applied to 56 patients, and a non-cross-linked resorbable collagen membrane (Jason membrane ${ }^{\circledR}$, Botiss biomaterials GmbH, Zossen, Germany) was additionally applied in 29 patients (Figure 1E). Subsequently, a releasing incision was applied to form a tensionless flap, and a primary suture was made using a non-resorbable monofilament (Rexlon 5-0 ${ }^{\circledR}$, Metavision Co., Seoul, Korea) (Figure 1F).
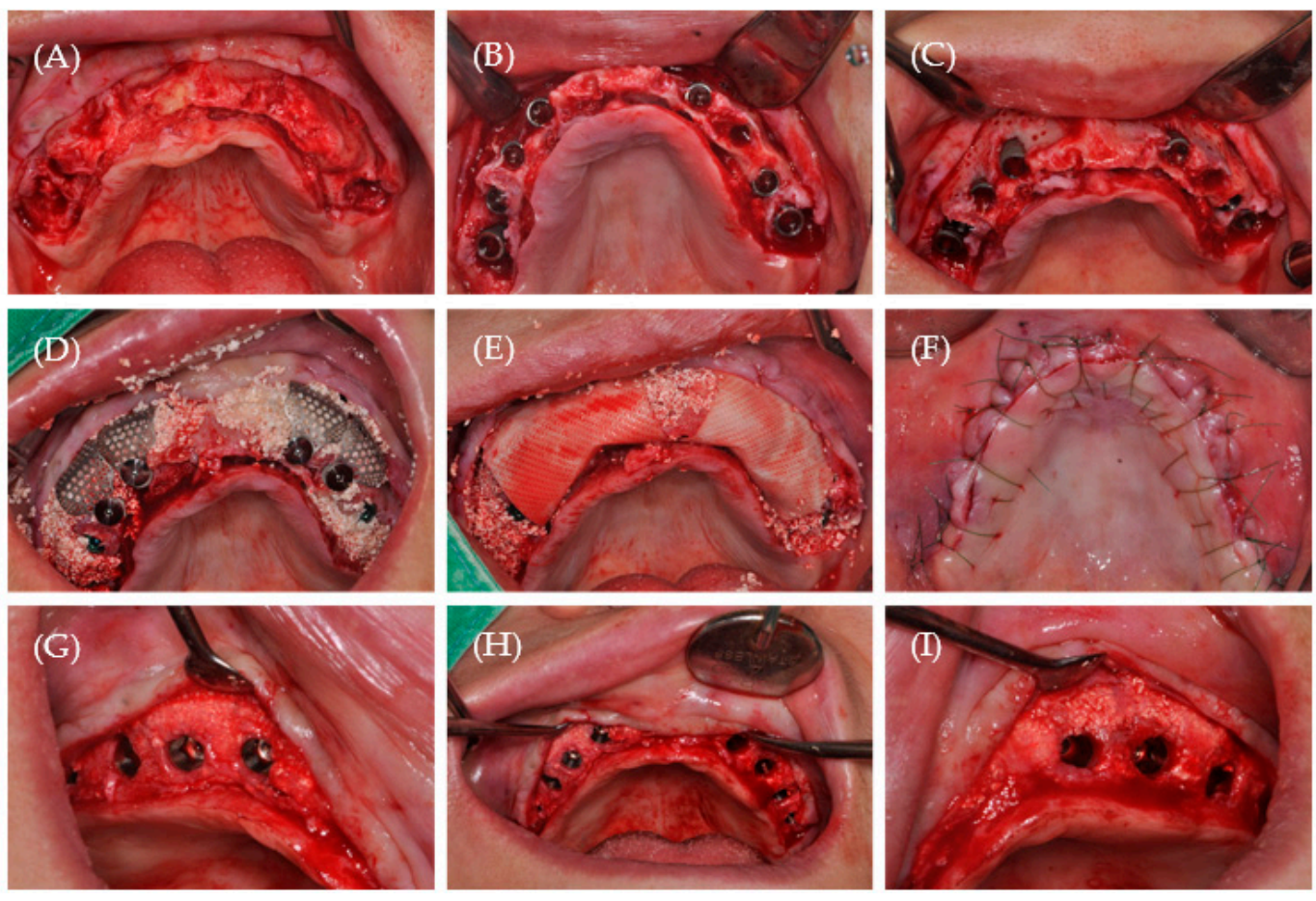

Figure 1. Surgical procedure. (A) Flap elevation, (B,C) Implantation, (D) Bone grafts and 3-D preformed titanium mesh application, (E) Collagen membrane application, (F) Suturing, and (G-I) Secondary implant surgery. 
Cone-beam computed tomography (CBCT; CB MercuRayTM; Hitachi, Tokyo, Japan) was performed, and antibiotics (Augmentin $625 \mathrm{mg}$, Ilsung Pharm. Co., Seoul, Korea) and analgesics (Aceclofenac $100 \mathrm{mg}$, Dona-A ST, Seoul, Korea) were administered orally for 7 days. In addition, the patients were taught to rinse the oral cavity with $0.12 \%$ chlorohexidine twice a day for 2 weeks. Surgical site dressing was performed for 1 week, and complete stitch-out was performed 2 weeks after the surgery.

After a healing period of approximately 6 months, a second surgery was performed to remove the 3-D preformed Ti mesh and mount the healing abutment. After a minimal incision for membrane removal, the full-thickness flap was elevated, and the cover and anchor screws for fixing the 3-D preformed Ti mesh were removed together with the mesh. A healing abutment of an appropriate diameter and height was fastened and sutured (Figure 1G-I).

$\mathrm{CBCT}$ was performed to evaluate the changes in the augmented bone just before the second surgery, and analgesics (Aceclofenac 100 mg, Dona-A ST, Seoul, Korea) were administered orally for 5 days.

\subsection{Results Analysis}

\subsubsection{Clinical Evaluation}

One hundred patients with 129 implants were generally evaluated 1 week, 2 weeks, 1 month, 3 months, and 6 months (secondary surgery) after the first surgery; the complications, such as infection and edema, and the 3-D preformed Ti-mesh exposure was evaluated. During the second surgery, the implant stability quotient (ISQ) was calculated for all implants. Prosthetic restoration was performed within 2-3 months after the second surgery, and all patients were followed up for at least 6 months after the final restoration.

\subsubsection{Radiological Evaluation}

For radiological evaluation, $\mathrm{CBCT}$ was performed for all the implants, under the same imaging conditions (FOV diameter, $10 \mathrm{~cm}$; FOV height, $5.6 \mathrm{~cm}$; acceleration voltage, $90 \mathrm{kV}$; beam currency, $8.0 \mathrm{~mA}$; voxel size, $0.2 \mathrm{~mm}$ ), preoperatively and immediately and six months (just before the second surgery) after the first surgery. The radiographic measurements were conducted by a single independent investigator (I.-O.C) who was not involved in the surgery and blinded to the group allocation. Cross-sectional CT images across the center of the implant in the metrology program (OnDemand 3-DTM; Cybermed, Seoul, Korea) were used to compare the amount of bone acquired from the non-contained horizontal defects, and the line perpendicular to the long axis of the implant was extended from the platform level to the buccal side to measure the distance to the outermost bone on the extension line (Figure 2). The length of the implant was measured, and measurement errors were corrected based on the magnification of the image in proportion to the actual length of the implant. To assess intra-examiner reliability, 20 randomly selected CT radiographs were measured twice with a 4-week interval between measurements. They were compared using the Pearson correlation coefficient $(r)$. A reliable repeatability frequency $(r>0.90)$ was also determined. All measurements were performed three times, and the average value was used. The amount of bone graft resorption (BR) was defined as the amount of grafted bone mass measured immediately after the first surgery (BA, bone augmentation immediately post-surgery) minus the amount of new hard tissue mass after 6 months (HG, hard tissue gain), and hard tissue gain rate (HGR) was defined as the percentage of HG compared with BA. 

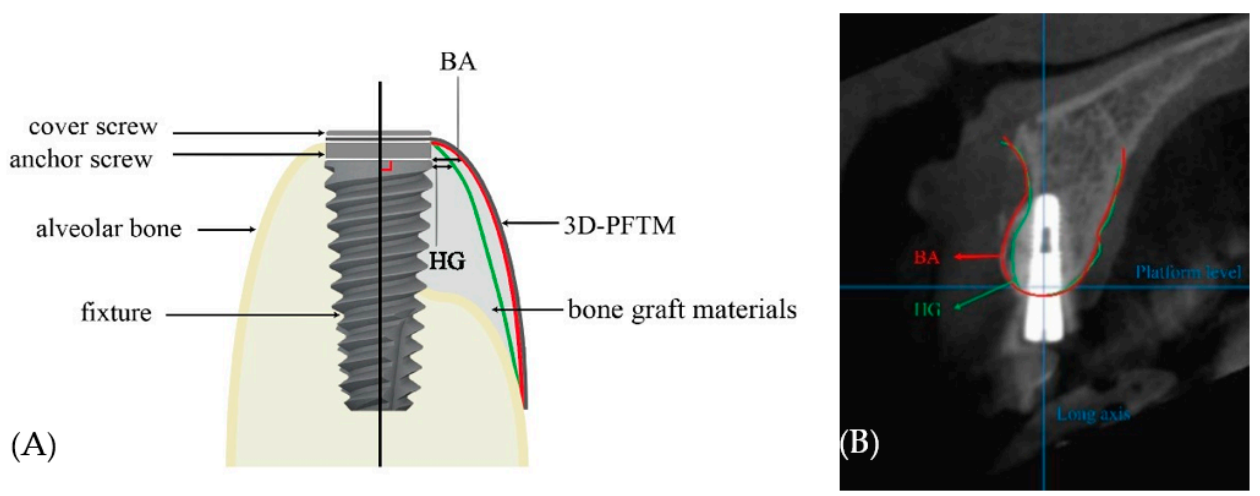

Figure 2. Method of radiographic analysis. (A) A line parallel to the long major axis of the implant is drawn, as well as a perpendicular line extending buccally at the level of the implant platform. (B) Table 3. D-PFTM, three-dimensional preformed titanium mesh; BA, bone augmentation immediately after surgery; HG, hard tissue gain after 6 months of healing.

\subsection{Statistical Analysis}

Each quantitative variable is expressed as an average and standard deviation. The data of Group 1, with less than 40 samples, were tested for normality using the KolmogorovSmirnov test, and those of Groups 2 and 3 were tested for normality using the Shapiro-Wilk test. To determine if there was a significant difference in the rate of bone formation among the three groups, the Kruskal-Wallis test, a non-parametric test, was performed, and the Mann-Whitney test was used to test for significance among the groups. The significance level was set at $p<0.05$. Statistical analysis was performed using SPSS version 22.0 for Windows (SPSS Inc., Chicago, IL, USA). The methodology was reviewed by an independent statistician.

\section{Results}

\subsection{Clinical Evaluation Results}

The clinical evaluation results are summarized in Table 2. Group 1 (only 3-D-PFTM) comprised 15 patients (seven men, eight women), and the average age was 64.5 years (3382 years). Implant placement was performed at 17 sites, and the average implant stability quotient (ISQ) measured during the second surgery was 78.9 \pm 3.8 . Mesh exposure occurred in two patients, one site for each of them, and the mesh exposure rate was $11.8 \%$. Group 2 (3-D-PFTM + cross-linked collagen membrane) comprised 56 patients (19 men, 37 women), with an average age of 56.5 years (21-81 years). Implant placement was performed at 72 sites, and the average ISQ value measured during the second surgery was $79.9 \pm 6.8$. Mesh exposure occurred in three patients, one site for each of them, and the mesh exposure rate was $4.2 \%$. Group 3 (3-D-PFTM + non-cross-linked collagen membrane) comprised 29 patients ( 13 men, 16 women) with an average age of 54.4 years (20-80 years). Implant placement was performed at 40 sites, and the average ISQ value measured during the second surgery was $77.0 \pm 7.4$. Mesh exposure occurred in two patients, and the mesh exposure rate was 5.0\%. The ISQ values of all three groups were 60 or higher, which indicates good implant osseointegration. A 2-fold decrease in the exposure rate was observed in the group that additionally used the resorbable collagen membrane than in the group that used only the 3-D preformed Ti mesh; using the cross-linked or non-crosslinked resorbable collagen membrane had no significant effect. One hundred patients in all three groups were followed up for at least 6 months after prosthetic restoration, and a total of 129 implants had a $100 \%$ survival rate. In addition, good secondary soft tissue healing was observed after 2 weeks of chlorhexidine gargle in all seven cases with mesh exposure, and there was no significant effect on prosthetic restoration and implant survival in the future. Late infection was also observed in two patients, but it was controlled with a 1-week antibiotic treatment and chlorhexidine gargle; they also recovered without a significant impact on implant survival. No other complications were observed. When the 
3-D preformed Ti mesh was removed for the second implant surgery after 6 months of healing, a layer of soft tissue was observed directly below the mesh.

Table 2. Clinical evaluation of the ISQ value, mesh exposure, and survival rate of implants in the groups.

\begin{tabular}{ccccc}
\hline & Group 1 & Group 2 & Group 3 & Total \\
\hline N of sites & 17 & 72 & 40 & 129 \\
ISQ, Mean \pm SD & $78.9 \pm 3.8$ & $79.9 \pm 6.8$ & $77.0 \pm 7.4$ & $79.0 \pm 6.7$ \\
Mesh exposure, N & 2 & 3 & 2 & 7 \\
Mesh exposure, (\%) & 11.8 & 4.2 & 5.0 & 5.4 \\
Survival rate of implant (\%) & 100 & 100 & 100 & 100
\end{tabular}

$\mathrm{N}$, number; SD, standard deviation; ISQ, implant stability quotient; Group 1, only three-dimensional preformed titanium mesh (3-D-PFTM) used; Group 2, 3-D-PFTM + cross-linked collagen membrane used; Group 3, 3-D-PFTM + non-cross-linked collagen membrane used.

\subsection{Radiological Evaluation Results}

The radiological evaluation results are summarized in Table 3. On the day of implant placement and GBR, the average BA was $3.7 \pm 1.1 \mathrm{~mm}$; it increased by $4.3 \pm 1.4 \mathrm{~mm}$ in Group 1, $3.7 \pm 1.0 \mathrm{~mm}$ in Group 2, and $3.6 \pm 1.0 \mathrm{~mm}$ in Group 3. There were no statistically significant differences among the amounts of augmentation in the groups $(p>0.05)$. The average HG at 6 months after implant placement was $3.1 \pm 1.3 \mathrm{~mm}$; it was $3.2 \pm 1.7$ $\mathrm{mm}$ in Group 1, $3.1 \pm 1.2 \mathrm{~mm}$ in Group 2, and $3.0 \pm 1.2 \mathrm{~mm}$ in Group 3. There was no statistically significant difference between the newly formed hard tissue masses of the groups $(p>0.05)$. The overall average BR was $0.7 \pm 0.9 \mathrm{~mm}$ : Group 1: $1.1 \pm 0.7 \mathrm{~mm}$; Group 2: $0.6 \pm 1.0 \mathrm{~mm}$; Group 3: $0.6 \pm 0.8 \mathrm{~mm}$. The overall HGR (HG/BA) was $82.4 \pm 22.4 \%$; HGR was $71.0 \pm 23.1 \%$ in Group 1, $84.2 \pm 21.5 \%$ in Group 2, and $84.0 \pm 22.9 \%$ in Group 3. Groups 2 and 3 showed significantly higher hard tissue gain rates than Group 1 (all $p<0.05)$. However, there was no statistically significant difference between the hard tissue gain rates of groups 2 and $3(p>0.05)$ (Figure 3$)$.

Table 3. Radiological assessment of the BA, HG, BR and HGR of the groups.

\begin{tabular}{|c|c|c|c|c|}
\hline & Group 1 & Group 2 & Group 3 & Total \\
\hline $\mathrm{BA}($ mean $\pm \mathrm{SD})$ & $4.3 \pm 1.4$ & $3.7 \pm 1.0$ & $3.6 \pm 1.0$ & $3.7 \pm 1.1$ \\
\hline$p$-value & & 0.187 & & \\
\hline $\mathrm{HG}($ mean $\pm \mathrm{SD})$ & $3.2 \pm 1.7$ & $3.1 \pm 1.2$ & $3.0 \pm 1.2$ & $3.1 \pm 1.3$ \\
\hline$p$-value & & 0.960 & & \\
\hline $\mathrm{BR}($ mean $\pm \mathrm{SD})$ & $1.1 \pm 0.7$ & $0.6 \pm 1.0$ & $0.6 \pm 0.8$ & $0.7 \pm 0.9$ \\
\hline$p$-value & $\begin{array}{c}0.006^{*} \\
\text { (vs. Group 2) } \\
0.007^{*} \\
\text { (vs. Group 3) }\end{array}$ & $\begin{array}{c}0.006^{*} \\
\text { (vs. Group 1) } \\
0.52 \\
\text { (vs. Group 3) }\end{array}$ & $\begin{array}{c}0.007^{*} \\
\text { (vs. Group 1) } \\
0.52 \\
\text { (vs. Group 2) }\end{array}$ & \\
\hline $\begin{array}{c}\text { HGR }(\text { mean } \pm \text { SD) } \\
(\%)\end{array}$ & $71.0 \pm 23.1$ & $84.2 \pm 21.5$ & $84.0 \pm 22.9$ & $82.4 \pm 22.4$ \\
\hline$p$-value & $\begin{array}{c}0.007 * \\
\text { (vs. Group 2) } \\
0.013 * \\
\text { (vs. Group 3) }\end{array}$ & $\begin{array}{c}0.007^{*} \\
\text { (vs. Group 1) } \\
0.528 \\
\text { (vs. Group 3) }\end{array}$ & $\begin{array}{c}0.013^{*} \\
\text { (vs. Group 1) } \\
0.528 \\
\text { (vs. Group 2) }\end{array}$ & \\
\hline
\end{tabular}

SD, standard deviation; BA, bone augmentation immediately after surgery; HG, hard tissue gain after 6 months of healing; BR, bone graft resorption (BA-HG); HGR, the percentage of HG compared with BA (HG/BA); Group 1, only three-dimensional preformed titanium mesh (3-D-PFTM); Group 2, 3-D-PFTM + cross-linked collagen membrane used; Group 3, 3-D-PFTM + non-cross-linked collagen membrane used. * Statistically significant difference $(p<0.05$; Kruskal-Wallis test). 


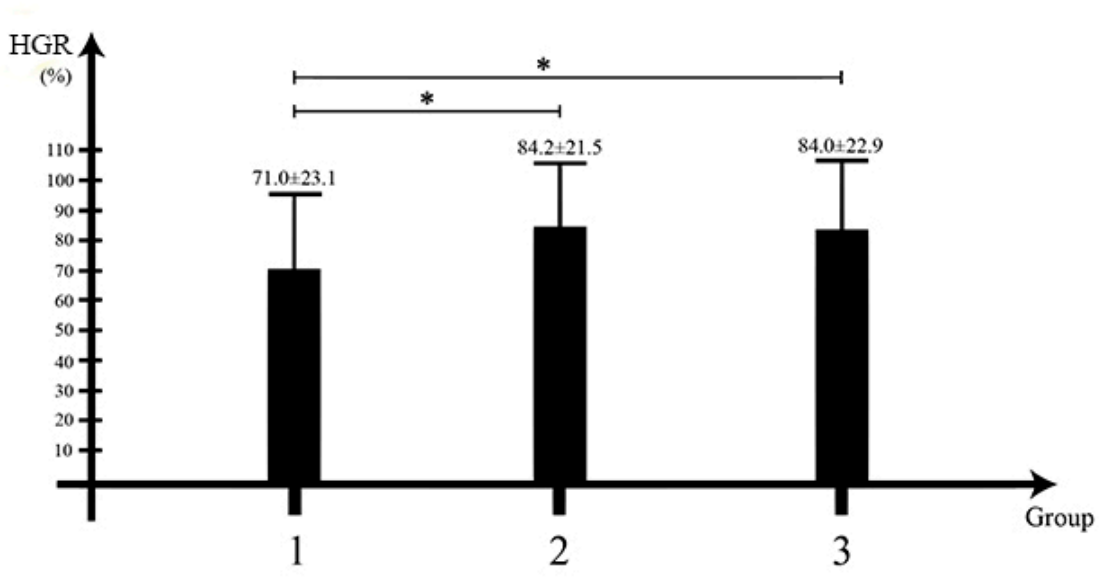

Figure 3. Comparison of the hard tissue gain rates (HGR) of the groups. There was a statistically significant difference between the rates of Groups 1 and 2, as well as Groups 1 and 3. HGR, the percentage of HG compared with BA (HG/BA); BA, bone augmentation immediately after surgery; HG, hard tissue gain after 6 months of healing; Group 1, only three-dimensional preformed titanium mesh (3-D-PFTM) used; Group 2, 3-D-PFTM + cross-linked collagen membrane used; Group 3, 3-D-PFTM + non-cross-linked collagen membrane used. * Statistically significant difference $(p<0.05$; Kruskal-Wallis test).

\section{Discussion}

This study involved 100 consecutive cases of GBR performed by applying a 3-D preformed Ti mesh to the non-contained horizontal defects around the implant simultaneously with implant placement. We evaluated and compared the clinical and radiologic results. We also grouped the cases using a cross-linked resorbable collagen membrane from those using a non-crosslinked collagen membrane with a 3-D preformed Ti mesh. We compared the exposure rate of the mesh and the hard tissue gain rate after 6 months to evaluate the effect of using an additional resorbable collagen membrane.

Conventional titanium meshes have an excellent self-space-making capacity, which provides predictable results when performing extensive bone grafting, and they are less susceptible to bacterial infection. In addition, they permit the supply of sufficient blood, nutrients, and oxygen, among others, because of their macropore sizes, which facilitate bone and soft tissue regeneration [14]. However, the conventional titanium mesh needs to be cut and bent to an appropriate size and shape before application, because complete fixation is required for positioning the mesh properly; the sensitivity of the technique is very high, and the mesh exposure frequency is high [15]. The mesh exposure rates reported in previous studies, such as those conducted by Rakhmatia that summarized the clinical studies on guided bone regeneration using the conventional titanium mesh, ranged from $14.28 \%$ to $52.7 \%$ [16]. Previous studies that used 3-D preformed Ti mesh have reported membrane exposure rates as high as $20-25 \%$, which are similar to those reported for the conventional titanium mesh $[17,18]$. However, Jung et al. reported that the 3-D preformed Ti mesh can reduce the duration of surgery and trauma to the flap because it does not need to be cut or bent differently from the existing Ti mesh, and there is no sharp margin [18]. In this study, mesh exposure was observed in 7 of the 100 patients and 7 of the 129 sites, and the exposure rate was as low as $5.4 \%$. The exposure rate of the 3-D preformed Ti mesh only group (Group 1) was $11.8 \%$, which was lower than that observed for the conventional titanium mesh. Despite these advantages, it is necessary to consider its relatively higher price than that of the traditional Ti mesh, and caution should be exercised when excessive vertical ridge augmentation is required.

Some studies have recommended the additional use of a resorbable collagen membrane above the titanium mesh to compensate for the limitations of the conventional titanium mesh [19-21]. Strietzel et al. reported that when a resorbable collagen mem- 
brane was used, fibrous tissue grew within the collagen membrane, thereby preventing dehiscence [22]. Lim et al., who studied this through animal experiments, reported that the additional use of a resorbable collagen membrane did not significantly decrease the exposure rate [21]. However, the exposure rate of the group using only a 3-D preformed Ti mesh (Group 1) was $11.8 \%$. In Groups 2 and 3, which additionally used the resorbable collagen membrane, the exposure rates were $5.0 \%$ and $4.2 \%$, respectively, which were lower than those of Group 1, regardless of whether the resorbable collagen membrane was cross-linked.

Several studies, including that of Grunder et al., have reported that a bone width of $2 \mathrm{~mm}$ or more is required on the buccal side at the platform level of the implant for the long-term stability of hard and soft tissues around the implant. If the bone width remains below $2 \mathrm{~mm}$, it may cause tissue retraction and aesthetic loss, and implant failure may also occur in severe cases [23-26]. However, Jiang et al. reported that the prognosis of GBR using a resorbable membrane is worsened, especially for lateral extrabony defects around the implant that do not exist in the envelope of adjacent bone [11]. In this study, we attempted to evaluate hard tissue gain in the non-contained horizontal defects of a 3-D preformed Ti mesh by measuring HG and HGR at the implant platform. In all cases, the average BA immediately after the first surgery was $3.7 \pm 1.1 \mathrm{~mm}$, and the hard tissue gain 6 months after the second surgery (HG) was averaged at $3.1 \pm 1.3 \mathrm{~mm}$. The HG of Groups 1, 2, and 3 were $3.2 \pm 1.7 \mathrm{~mm}, 3.1 \pm 1.2 \mathrm{~mm}$, and $3.0 \pm 1.2 \mathrm{~mm}$, respectively; hard tissue gains of $2 \mathrm{~mm}$ or more were observed in all the groups. This was consistent with the findings of previous studies that performed guided bone regeneration simultaneously with implant placement using a 3-D preformed Ti mesh; these studies reported buccal hard tissue gains of more than $2 \mathrm{~mm}[18,27]$. Mir-Mari et al. reported that when only resorbable collagen membrane and bone graft material were used, approximately $40 \%$ of horizontal graft loss occurred immediately after suturing [28]. According to a study by Schwarz et al., the displacement of the graft and the membrane after 9 weeks in the case of GBR using only the resorbable collagen membrane and graft in the buccal dehiscence region significantly worsens the prognosis of bone regeneration [29]. The growth of excellent hard tissue in the buccal extrabony defects of the implant during guided bone regeneration using a 3-D preformed Ti mesh may be attributed to the secure anti-pressure effect at the platform level, which is fixed by the implant fixture, unlike for resorbable membranes, for which it is difficult to maintain space due to the compression of soft tissues [30].

However, the 3-D preformed Ti mesh and the conventional titanium mesh can penetrate soft tissues owing to the macropore structure of the membrane [31-33]. This soft tissue layer is also called pseudo-periosteum; the histological component is a dense connective tissue, and it has low cellularity and is non-mineralized [32,34]. Therefore, radiolucency was observed below the titanium mesh in the radiographic images. The average bone graft resorption was $0.67( \pm 0.92) \mathrm{mm}$ in all 129 implants, $1.10( \pm 0.71) \mathrm{mm}$ in Group 1, $0.62( \pm 0.98) \mathrm{mm}$ in Group 2, and $0.55( \pm 0.79) \mathrm{mm}$ in Group 3. Based on the results of this study, the formation of pseudo-periosteum can be reduced when a resorbable collagen membrane, regardless of whether it is cross-linked, is used. This was consistent with the findings of the study by Proussaefs et al., who reported that the formation of pseudoperiosteum was inhibited when a resorbable collagen membrane was used with a titanium mesh [35].

The hard tissue gain rate (HGR) was $81.2 \%$ in the study by Artzi et al., who previously measured HGR using only a conventional titanium mesh, $85 \%$ in the study by Corinaldesi et al., and $83.3 \%$ in the study by Roccuzzo et al. [36-38]. In animal experiments by Shin et al., an improved hard tissue acquisition was observed in the group using the Ti mesh with a resorbable collagen membrane compared with the group using the Ti mesh alone [39]. In the study by Funato et al., when a resorbable collagen membrane was additionally used, HGR was $87.3 \%$, which was higher than that reported in a study using only the conventional titanium mesh [40]. In this study, the average HGR of the 129 bone graft sites was approximately $82.4 \pm 22.4 \%$, which was similar to those reported in previous 
studies. HGR was $71.0 \%, 84.2 \%$, and $84 \%$ for Groups 1, 2, and 3, respectively; Groups 2 and 3 demonstrated significantly higher rates than Group $1(p<0.05)$. However, there was no significant difference between the rates in groups 2 and $3(p>0.05)$. In other words, this study showed a higher rate of hard tissue gain with fewer pseudo-periosteums in Groups 2 and 3, which used an additional resorbable collagen membrane. No difference was attributable to the use of the cross-linked resorbable collagen membrane. When using a conventional technique, most of the bone graft is completely covered by the titanium mesh, and it is tightly fixed to the marginal area using a titanium screw. Because of the structure of the 3-D preformed Ti mesh, which only sits on the bone graft and is fixed only at the implant, soft tissue invasion of the marginal area is expected to be greater. In this study, the HGR of Group 1 was lower than that of the conventional titanium mesh group. It seems that by using a resorbable membrane to compensate for this structural limitation, an additional soft-tissue blockade was added to the marginal area of the 3-D preformed Ti mesh, increasing the HGR.

This study was retrospective and had limitations. In this study, there was no control over other conditions that could affect the results of the GBR, such as the patient's age, placement location, the condition of soft tissue [41], and the size of peri-implant bony defects. There was also no consideration of systemic condition that affect the postsurgical healing, such as smoking, periodontitis [42], and oral anticoagulant therapy [43]. Therefore, it is necessary to evaluate the effectiveness of the 3-D preformed Ti mesh using prospective research in the future. In addition, the artifacts may have been caused by existing metals, which may have limited the radiographic evaluations. The measurements of the hard tissue mass may have also been incorrect because they were measured directly by evaluators using the measurement program. In addition, since the follow-ups for all the cases were short-term, the analyses of the mid-term and long-term results are recommended.

\section{Conclusions}

Within the limitations of this study, we concluded that the hard tissue gain can be facilitated by using a 3-D preformed Ti mesh in GBR for a non-contained horizontal defect on the buccal side of the implant simultaneously with implant placement. The addition of a resorbable collagen membrane, regardless of whether it is cross-linked, can increase the hard tissue gain rate by reducing the exposure of the titanium mesh and inhibiting soft tissue penetration.

Author Contributions: Conceptualization, W.-P.L.; methodology, S.-J.Y.; validation, J.-S.O.; formal analysis, B.-O.K.; investigation, I.-O.C.; resources, W.-P.L.; data curation, I.-O.C.; writing-original draft preparation, I.-O.C.; writing-review and editing, J.-S.O., S.-J.Y., B.-O.K., and W.-P.L.; visualization, I.-O.C.; supervision, W.-P.L.; project administration, W.-P.L. All authors have read and agreed to the published version of the manuscript.

Funding: This research received no external funding.

Institutional Review Board Statement: This study was conducted in accordance with the guidelines of the Declaration of Helsinki and approved by the Institutional Review Board of the Dental Hospital of Chosun University in Gwangju, Korea (CUDHIRB-1806-005).

Informed Consent Statement: Informed consent was obtained from all subjects involved in the study.

Data Availability Statement: The datasets generated or analyzed during the current study are available from the corresponding author on reasonable request.

Acknowledgments: The authors thank Dong-Su Lee (Department of Computer Science and Statistics, Chosun University, Gwangju, Korea) for the statistical consultation and some of the data analysis. This study was supported by a research fund from Chosun University in 2017.

Conflicts of Interest: The authors declare no conflict of interest. 


\section{References}

1. Beirne, U.; Branemark, P. Reconstruction of alveolar jaw bone: An experimental and clinical study of immediate and preformed autologous bone grafts in combination with osseointegrated implants. Scand. J. Plast. Reconstr. Surg. 1980, 14, 23-48. [CrossRef] [PubMed]

2. Bassetti, M.A.; Bassetti, R.G.; Bosshardt, D.D. The alveolar ridge splitting/expansion technique: A systematic review. Clin. Oral Implant. Res. 2016, 27, 310-324. [CrossRef] [PubMed]

3. Hong, J.Y.; Baek, W.S.; Cha, J.K.; Lim, H.C.; Lee, J.S.; Jung, U.W. Long-term evaluation of sinus floor elevation using a modified lateral approach in the posterior maxilla. Clin. Oral Implant. Res. 2017, 28, 946-953. [CrossRef]

4. Lorenzoni, M.; Pertl, C.; Polansky, R.; Wegscheider, W. Guided bone regeneration with barrier membranes-a clinical and radiographic follow-up study after 24 months. Clin. Oral Implant. Res. 1999, 10, 16-23. [CrossRef] [PubMed]

5. Shet, U.K.; Cho, M.S.; Hur, J.W.; Oh, C.J.; Chung, K.; Park, H.J.; Kook, M.S.; Jung, S.G.; Oh, H.K. Evaluation of augmented alveolar bone and dental implant after autogenous onlay block bone graft. J. Korean Dent. Assoc. 2012, 50, 329-338.

6. Aghaloo, T.L.; Misch, C.; Iacono, V.J.; Wang, H.L. Bone augmentation of the edentulous maxilla for implant placement: A systematic review. Int. J. Oral Maxillofac. Implant. 2016, 31, 19S-30S. [CrossRef]

7. Wessing, B.; Lettner, S.; Zechner, W. Guided bone regeneration with collagen membrane and particulate graft materials: A systematic review and meta-analysis. Int. J. Oral Maxillofac. Implant. 2018, 33, 87-100. [CrossRef]

8. Benic, G.I.; Hämmerle, C.H. Horizontal bone augmentation by means of guided bone regeneration. Periodontol. 2000 2014, 66, 13-40. [CrossRef]

9. Mir-Mari, J.; Wui, H.; Jung, R.E.; Hämmerle, C.H.; Benic, G.I. Influence of blinded wound closure on the volume stability of different GBR materials: An in vitro cone-beam computed tomographic examination. Clin. Oral Implant. Res. 2016, 27, 258-265. [CrossRef]

10. Bogaerde, L.V. A proposal for the classification of bony defects adjacent to dental implants. Int. J. Periodontics Restor. Dent. 2004, 24, 264-271.

11. Jiang, X.; Zhang, Y.; Di, P.; Lin, Y. Hard tissue volume stability of guided bone regeneration during the healing stage in the anterior maxilla: A clinical and radiographic study. Clin. Implant Dent. Relat. Res. 2018, 20, 68-75. [CrossRef] [PubMed]

12. Herzberg, R. Vertical guided bone regeneration for a single missing tooth span with titanium-reinforced d-PTFE membranes: Clinical considerations and observations of 10 consecutive cases with up to 36 months follow-up. Int. J. Periodontics Restor. Dent. 2017, 37, 893-899. [CrossRef] [PubMed]

13. Lee, S.H.; Moon, J.H.; Jeong, C.M.; Bae, E.B.; Park, C.E.; Jeon, G.R.; Lee, J.J.; Jeon, Y.C.; Huh, J.B. The mechanical properties and biometrical effect of 3D preformed titanium membrane for guided bone regeneration on alveolar bone defect. Biomed. Res. Int. 2017, 2017, 7102123. [CrossRef] [PubMed]

14. Her, S.; Kang, T.; Fien, M.J. Titanium mesh as an alternative to a membrane for ridge augmentation. J. Oral Maxillofac. Surg. 2012, 70, 803-810. [CrossRef] [PubMed]

15. Elgali, I.; Omar, O.; Dahlin, C.; Thomsen, P. Guided bone regeneration: Materials and biological mechanisms revisited. Eur. J. Oral Sci. 2017, 125, 315-337. [CrossRef]

16. Rakhmatia, Y.D.; Ayukawa, Y.; Furuhashi, A.; Koyano, K. Current barrier membranes: Titanium mesh and other membranes for guided bone regeneration in dental applications. J. Prosthodont. Res. 2013, 57, 3-14. [CrossRef]

17. Zita Gomes, R.; Paraud Freixas, A.; Han, C.H.; Bechara, S.; Tawil, I. Alveolar ridge reconstruction with titanium meshes and simultaneous implant placement: A retrospective, multicenter clinical study. Biomed. Res. Int. 2016, 2016, 1-12. [CrossRef]

18. Jung, G.U.; Jeon, J.Y.; Hwang, K.G.; Park, C.J. Preliminary evaluation of a three-dimensional, customized, and preformed titanium mesh in peri-implant alveolar bone regeneration. J. Korean Assoc. Oral Maxillofac. Surg. 2014, 40, 181-187. [CrossRef]

19. Degidi, M.; Scarano, A.; Piattelli, A. Regeneration of the alveolar crest using titanium micromesh with autologous bone and a resorbable membrane. J. Oral Implantol. 2003, 29, 86-90. [CrossRef]

20. Salama, H.; Garber, D. Three-dimensional bone and soft tissue requirements for optimizing esthetic results in compromised cases with multiple implants. Int. J. Periodontics Restor. Dent. 2010, 30, 503-511.

21. Lim, H.C.; Lee, J.S.; Choi, S.H.; Jung, U.W. The effect of overlaying titanium mesh with collagen membrane for ridge preservation. J. Periodontal Implant Sci. 2015, 45, 128-135. [CrossRef] [PubMed]

22. Strietzel, F.P.; Khongkhunthian, P.; Khattiya, R.; Patchanee, P.; Reichart, P.A. Healing pattern of bone defects covered by different membrane types-A histologic study in the porcine mandible. J. Biomed. Mater. Res. B Appl. Biomater. 2006, 78, 35-46. [CrossRef] [PubMed]

23. Grunder, U.; Gracis, S.; Capelli, M. Influence of the 3-D bone-to-implant relationship on esthetics. Int. J. Periodontics Restor. Dent. 2005, 25, 113-119.

24. Spray, J.R.; Black, C.G.; Morris, H.F.; Ochi, S. The influence of bone thickness on facial marginal bone response: Stage 1 placement through stage 2 uncovering. Ann. Periodontol. 2000, 5, 119-128. [CrossRef]

25. Qahash, M.; Susin, C.; Polimeni, G.; Hall, J.; Wikesjö, U.M. Bone healing dynamics at buccal peri-implant sites. Clin. Oral Implant. Res. 2008, 19, 166-172. [CrossRef]

26. Merheb, J.; Quirynen, M.; Teughels, W. Critical buccal bone dimensions along implants. Periodontology 2000 2014, 66, 97-105. [CrossRef] 
27. Sakr, A.A.; Shaaban, A.M.; Elsheikh, S.A. Evaluation of the effect of i-gen titanium membrane around immediate dental implants replacing posterior mandibular tooth with buccal bone defect. Alex. Dent. J. 2017, 42, 85-91. [CrossRef]

28. Mir-Mari, J.; Benic, G.I.; Valmaseda-Castellón, E.; Hämmerle, C.H.; Jung, R.E. Influence of wound closure on the volume stability of particulate and non-particulate GBR materials: An in vitro cone-beam computed tomographic examination. Part II. Clin. Oral Implant. Res. 2017, 28, 631-639. [CrossRef]

29. Schwarz, F.; Herten, M.; Ferrari, D.; Wieland, M.; Schmitz, L.; Engelhardt, E.; Becker, J. Guided bone regeneration at dehiscencetype defects using biphasic hydroxyapatite+ beta tricalcium phosphate (Bone Ceramic ${ }^{\circledR}$ ) or a collagen-coated natural bone mineral (BioOss Collagen ${ }^{\circledR}$ ): An immunohistochemical study in dogs. Int. J. Oral Maxillofac. Surg. 2007, 36, 1198-1206. [CrossRef]

30. Jiang, X.; Zhang, Y.; Chen, B.; Lin, Y. Pressure bearing device affects extraction socket remodeling of maxillary anterior tooth. A prospective clinical trial. Clin. Implant Dent. Relat. Res. 2017, 19, 296-305. [CrossRef]

31. Corinaldesi, G.; Pieri, F.; Marchetti, C.; Fini, M.; Aldini, N.N.; Giardino, R. Histologic and histomorphometric evaluation of alveolar ridge augmentation using bone grafts and titanium micromesh in humans. J. Periodontol. 2007, 78, 1477-1484. [CrossRef] [PubMed]

32. Proussaefs, P.; Lozada, J. Use of titanium mesh for staged localized alveolar ridge augmentation: Clinical and histologichistomorphometric evaluation. J. Oral Implantol. 2006, 32, 237-247. [CrossRef]

33. Pieri, F.; Corinaldesi, G.; Fini, M.; Aldini, N.N.; Giardino, R.; Marchetti, C. Alveolar ridge augmentation with titanium mesh and a combination of autogenous bone and anorganic bovine bone: A 2-year prospective study. J. Periodontol. 2008, 79, $2093-2103$. [CrossRef]

34. Simion, M.; Jovanovic, S.A.; Trisi, P.; Scarano, A.; Piattelli, A. Vertical ridge augmentation around dental implants using a membrane technique and autogenous bone or allografts in humans. Int. J. Periodontics Restor. Dent. 1998, 18, 9-23.

35. Proussaefs, P.; Lozada, J. The use of resorbable collagen membrane in conjunction with autogenous bone graft and inorganic bovine mineral for buccal/labial alveolar ridge augmentation: A pilot study. J. Prosthet. Dent. 2003, 90, 530-538. [CrossRef]

36. Artzi, Z.; Dayan, D.; Alpern, Y.; Nemcovsky, C.E. Vertical ridge augmentation using xenogenic material supported by a configured titanium mesh: Clinicohistopathologic and histochemical study. Int. J. Oral Maxillofac. Implant. 2003, 18, 440-446.

37. Corinaldesi, G.; Pieri, F.; Sapigni, L.; Marchetti, C. Evaluation of survival and success rates of dental implants placed at the time of or after alveolar ridge augmentation with an autogenous mandibular bone graft and titanium mesh: A 3-to 8-year retrospective study. Int. J. Oral Maxillofac. Implant. 2009, 24, 1119-1128.

38. Roccuzzo, M.; Ramieri, G.; Bunino, M.; Berrone, S. Autogenous bone graft alone or associated with titanium mesh for vertical alveolar ridge augmentation: A controlled clinical trial. Clin. Oral Implant. Res. 2007, 18, 286-294. [CrossRef]

39. Shin, S.I.; Herr, Y.; Kwon, Y.H.; Chung, J.H. Effect of a collagen membrane combined with a porous titanium membrane on exophytic new bone formation in a rabbit calvarial model. J. Periodontol. 2013, 84, 110-116. [CrossRef]

40. Funato, A.; Ishikawa, T.; Kitajima, H.; Yamada, M.; Moroi, H. A novel combined surgical approach to vertical alveolar ridge augmentation with titanium mesh, resorbable membrane, and rhPDGF-BB: A retrospective consecutive case series. Int. J. Periodontics Restor. Dent. 2013, 33, 437-445. [CrossRef]

41. Scarano, A.; Bernardi, S.; Rastelli, C.; Mortellaro, C.; Vittorini, P.; Falisi, G. Soft tissue augmentation by means of silicon expanders prior to bone volume increase: A case series. J. Biol. Regul. Homeost. Agents 2019, 33, 77-84. [PubMed]

42. Matarese, G.; Isola, G.; Anastasi, G.P.; Cutroneo, G.; Cordasco, G.; Favaloro, A.; Vita, G.; Vermiglio, G.; Milardi, D.; Zizzari, V.L.; et al. Transforming growth factor beta 1 and vascular endothelial growth factor levels in the pathogenesis of periodontal disease. Eur. J. Inflamm. 2013, 11, 479-488. [CrossRef]

43. Isola, G.; Matarese, G.; Cordasco, G.; Rotondo, F.; Crupi, A.; Ramaglia, L. Anticoagulant therapy in patients undergoing dental interventions: A critical review of the literature and current perspectives. Minerva Stomatol. 2015, 64, 21-46. [PubMed] 